\title{
STATISTICAL EVALUATION AND ANALYSIS OF MUTUAL INTERACTION OF COMPONENTS
}

\author{
A. Gališanskis, V. Giniotis \\ $A B$ „Lietuvos avialinijos“, Vilnius Gediminas Technical University, Dept. of Geodesy and Cadastre, \\ Sauletekio al.11,LT-10223 Vilnius-40,Lithuania.E-mail:vg@ai.vtu.lt
} Received 1703 2006, accepted 07092006

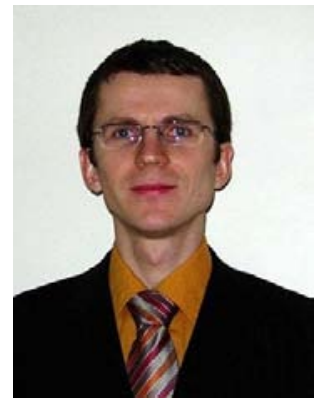

\section{Artūras GALIŠANSKIS}

Date of birth: 1975 .

Education: Vilnius Gediminas Technical University, Antanas Gustaitis Aviation Institute: Bachelor's Degree in Mechanical Science (1998), Master's Degree in Mechanical Science (2000). At present is working in aviation industry. Present position: $A B$,Lietuvos avialinijos “.,

Publications: 4 scientific papers.

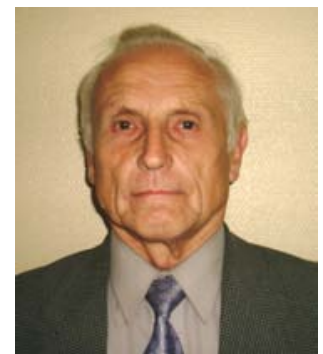

Vytautas GINIOTIS, Prof Dr Habil

Affiliations and functions: Has participated in many international conferences, and research and lecture visits to Germany, Austria and UK universities.

Research interests: 3D measurements and instrumentation, automatisation of measurements, angular measurements. Publications: Author of one and co-author of another monograph and more than 160 scientific papers.

\begin{abstract}
One of the most basic methods of reducing maintenance costs in civil aviation is discussed in this paper. This method, which is used by transport carriers, is a reliability programme. The parameters applied in this programme are described in case as they express the numerical evaluation of failure of aircraft components. Nevertheless, such evaluation permits to assess only the selected components. Other statistical methods must be used to assess the reliability of an entire technical system. For this purpose, a correlation and regression analyses are applied to analyse an entire aircraft system, and some results of this investigation are presented here.
\end{abstract}

Keywords: measurement, quality, failure, reliability programme, correlation, regression.

\section{Introduction}

Aviation safety, the evaluation of airworthiness and other flight quality requirements depend on the operability of many interconnected units and components of an aircraft system. The significance of those units in the system is not equal, so there is no single criterion for their assessment or repair or replacement time during their exploitation and maintenance operations. Some practical testing and measuring investigations are performed before stating their endurance or replacement periods. An analysis of statistical means possible to use for the numerical assessment and quality control of components connected in the aircraft system is presented here.

\section{Assessment criteria of component efficiency}

Production in machine engineering is tightly connected with ubiquitous measurement and testing processes beginning from technological operations to the evaluation of the complex technical parameters during the issue of the final product. It is not the final measurement operations because quality control and testing took place during all product service period. These processes are of the utmost importance in aviation since they are connected with passenger (and aircraft) safety. For safety and reliability of the aircraft some endurance periods are warranted. This serves as a measure of working hours to determine the safe operation of a unit, component, or 
entire machine. This parameter is also assessed by reliability parameters in aviation. A reliability programme can have various levels of complexity depending on the complexity of the equipment being used. The goals of a company are also among the factors that must be considered.

During the exploitation of an aircraft, four component reliability assessment parameters are mostly used [6]. They are $T_{M T B R}(\mathrm{MTBR}$ - Mean Time Between Removals), $T_{\text {MTBUR }}$ (MTBUR - Mean Time Between Unscheduled Removals), $\mathrm{T}_{\mathrm{MTBF}}$ (MTBF - Mean Time Between Failure), $k_{U R R}$ (URR - Unscheduled Removal Rate). These expressions are used for their calculation:

$$
\begin{aligned}
& T_{\text {MTBR }}=\frac{H \times N}{n_{g}} ; T_{M T B U R} \frac{H \times N}{n_{u}} ; \\
& T_{M T B F}=\frac{H \times N}{n_{f}} ; k_{U R R}=\frac{n_{u} \times 1000}{H \times N} ; \\
& k_{U R R}=\frac{1000}{T_{M T B U R}} .
\end{aligned}
$$

All dimensions are in $h$.

Where $H$ - aircraft flying hours during some period; $N$ - number of the same components in the aircraft;

$n_{g}$ - general number of component changes;

$n_{u}$ - number of unscheduled component changes;

$n_{f}$ - number of component failures.

The parameter $\mathrm{T}_{\mathrm{MTBR}}$ includes the assessment of all types of removals such as unscheduled removals and modifications. Using this parameter can assess all costs of removing the component from the aircraft. The parameter $T_{\text {MTBUR }}$ relates only to unscheduled removals that were determined during the search for failures. Nevertheless, an unscheduled removal does not mean that there was a failure of this component. This can be proved only at the component repair station using special test benches. If such a need exists, the component can be disassembled. For the $T_{M T B F}$ control, a carrier must have information about the repairs of the component, i.e. whether the component was properly removed and whether the failure was proved at the repair organization. $k_{U R R}$ is expressed as a value for 1000 hours of work, and the $k_{U R R}$ parameter is inversely proportional to $T_{M T B U R}$.

These parameters further are compared with the determined level of reliability (UCL - upper control limit, LCL - lower control limit). This level is determined on the basis of data from a previous period (Fig 1). If the parameter under control (usually $k_{U R R}$ ) exceeds the limit calculated according to equation (2), relevant correctional actions must be undertaken to enhance the reliability of the component. Lower and upper control limits can be found by:

$$
C L=\bar{x} \pm k S \text {. }
$$

Where $\bar{x}$ - statistical mean value;

$S$ - standard deviation;

$k$ - coefficient depending on probability, usually equal to $2,2.5$, or 3 .
In general, for an analysis of component failure, the Poisson distribution law is applied, and the normal distribution law is used in cases when failure is directly dependant on the function of time, for example the wheels of undercarriage or brakes.

$\bar{x}=\lambda, S=\sqrt{\lambda}$ in case of Poisson distribution.

The control limits are determined as

$$
C L=\lambda \pm k \sqrt{\lambda}
$$

Here $\lambda=n \times p$-distribution parameter;

$$
p \text { - probability of event. }
$$

A diagram for the assessment of $k_{U R R}$ is shown in figure 1 (at $k=2$ ), where it can be determined in which period $k_{U R R}$ exceeds an upper limit. The data are taken from the exploitation register of one aircraft type. When the parameter exceeds an upper limit once, it is no reason to consider it an alarming factor. Only if the parameter exceeds an upper limit two or three times can it be treated as a systematic occurrence. Correctional actions are then needed which, if appropriately undertaken, should return the parameter to the lower zone of the limit. The lower control limit is used for observing a progress of the parameter.

On the basis of the analysis presented here, it is possible to change the programme of maintenance, i.e. the intervals of periodic maintenance, the method of maintenance, the place, etc. might be changed. This failure analysis is quantitative and could be applied to one type of component. Equations (1-2) express the "traditional" reliability programme. With the purpose of looking through the entirety of the system, other statistical methods such as regression and correlation analyses must be applied.

\section{Analysis of mutual interaction of components}

\subsection{Assessment of two parameters of the aircraft system}

Its working hours or relative numerical parameters can assess the efficiency of every component. It is important to apply statistical methods that help to determine the quantitative characteristic of objects. They are also very effective in creating new methods for investigating production control efficiency [1, 10, 4]. Statistical methods of assessment can be applied during the entire cycle of product survival, beginning from market analysis and presentation to customer to final disposal [10].

For the investigation of the mutual relationship between components, the regression and correlation method will be applied. The task of this investigation is to assess a mutual relationship of two or more components and to find out, how strong it is.

For such assessment, the aircraft electrical equipment system which consists of five components, was chosen: 
1. AC Generator.

2. AC Generator Control Unit.

3. AC Power Inverter.

4. Transformer Rectifier Unit.

5. Battery.

As initial information about the failure data of these components, twelve quarters were used (Fig 2).

It is evident from these data that the most important problem in this system is the AC Generator. Its unscheduled removal number makes up about $38 \%$ of all removals; nevertheless, it is not a dominant component. According to such initial information, it would be difficult to judge where the problem of the reliability of all equipment exists. Pareto analysis cannot be applied in such a case either [9]. [14]:

The regression formula is written in general form

$$
y_{i}=\beta_{1} c_{i 1}+\beta_{2} c_{i 2}+\ldots+\beta_{p} c_{i p}+\varepsilon_{i},
$$

$\mathrm{I}=1, \ldots, \mathrm{n}$.

Where $c_{i j}$-known permanent values, $\mathrm{c}_{\mathrm{i} 1}=0$ for all I;

$\beta_{\mathrm{j}}$ - unknown parameters;

$\mathcal{E}_{I}$ - independent random values with probability distribution $\mathrm{NN}\left(0, \sigma^{2}\right)$.

There are many references $[1,14,17,8]$ in which regression and correlation expressions of two parameters could be found. Their numerical values are calculated by means of some mathematical packages, so using the formulas of regression and correlation parameters together with data shown in figure 2, the data from correlation and regression analysis can be calculated. The least squares method is used for calculation of regression. The correctness of the calculation of correlation coefficient $\mathrm{r}$ is checked using the $t$ criterion [2]:

$$
t=\frac{r \cdot \sqrt{n-2}}{\sqrt{1-r^{2}}}
$$

Where $r$ - correlation coefficient; $n$ - number of correlating pairs.

The analysis performed (Attachment) shows a mutual correlation between three components, i.e. their coefficient of correlation is adequate; the value of their $t$ criterion obtained by calculating according to equation (4) is bigger than the determined distribution probability at $(n-2)$ number of correlating parameters [1]. Using the Student's t distribution table, it was determined that the value $t$ is 1.8125 at significance level $\alpha=0.05$ and the degree of freedom $(n-2=10)$. Mutual interaction of components is shown in figure 3 , and diagrams of regression figure 4 , the highest mutual relationship is between the AC Power Inverter and the Transformer Rectifier Unit (a). The mutual relationship between the Battery and the AC Power Inverter is almost at the same level (b and c).

It must also be determined, whether these components have any functional interaction, and in this case the requirement is met. At the same time, a malfunction of one component will interact into the malfunction of the other and together they will exert a greater influence on the operability of the entire machine or system.

\subsection{Correlation analysis of three objects}

When the number of objects is more than two, a multimember regression equation must be solved. The simplest case is when this number is equal to three, and the objects are linked by linear dependence [17]. Then the equation (3) will be expressed as:

$$
z=a x+b y+c
$$

Where $a$ and $b$ - regression coefficients; $c$ - coefficient.

To solve the equation (5) by the least squares method, it is convenient to write it as:

$$
z-\bar{z}=a(x-\bar{x})+b(y-\bar{y})
$$

where $a=\frac{r_{x z}-r_{y z} r_{x y}}{1-r_{x y}^{2}} \times \frac{S_{z}}{S_{x}} ; b=\frac{r_{y z}-r_{x z} r_{x y}}{1-r_{x y}^{2}} \times \frac{S_{z}}{S_{y}}$.

Where $r_{x z}, r_{y z}, r_{x y}$ - correlation coefficients between the variables $x$ and $z ; y$ and $z ; x$ and $y$;

$$
S_{\mathrm{x}}, S_{\mathrm{y}}, S_{\mathrm{z}}-\text { standard deviations. }
$$

$r_{x z}, r_{y z}, r_{x y}$ are found using usual statistical formulas for two-parameter correlation determination.

If there are three data pairs ( $\mathrm{x}, \mathrm{y}$ and $\mathrm{z}$ ), the correlation coefficient is determined by this formula [17]:

$$
R_{(x, y, z)}=\sqrt{\frac{r_{x z}^{2}-2 r_{x y} r_{x z} r_{y z}+r_{y z}^{2}}{1-r_{x y}^{2}}}
$$

The partial sample values of correlation coefficients or relation between $z$ and $x$ (at invariable y) and between $z$ and $y$ (at invariable $x$ ) are determined by these equations [17]:

$$
\begin{aligned}
& r_{x z(y)}=\frac{r_{x z}-r_{x y} r_{y z}}{\sqrt{\left(1-r_{x y}^{2}\right)\left(1-r_{y z}^{2}\right)}} ; \\
& r_{y z(x)}=\frac{r_{y z}-r_{x y} r_{x z}}{\sqrt{\left(1-r_{x y}^{2}\right)\left(1-r_{x z}^{2}\right)}}
\end{aligned}
$$

These coefficients have the same features as usual correlation coefficients, i.e. they are used to evaluate the relationship between the data pairs. For such an evaluation the same formulas used to evaluate the two data pairs obtained from the regression and correlation calculations.

At first, the table of components having a mutual relationship is compiled, including estimates of $\bar{x}$ and $S$ (Tab). The AC Power Inverter has designation (x), the Transformer Rectifier Unit (y), and the Battery (z). 


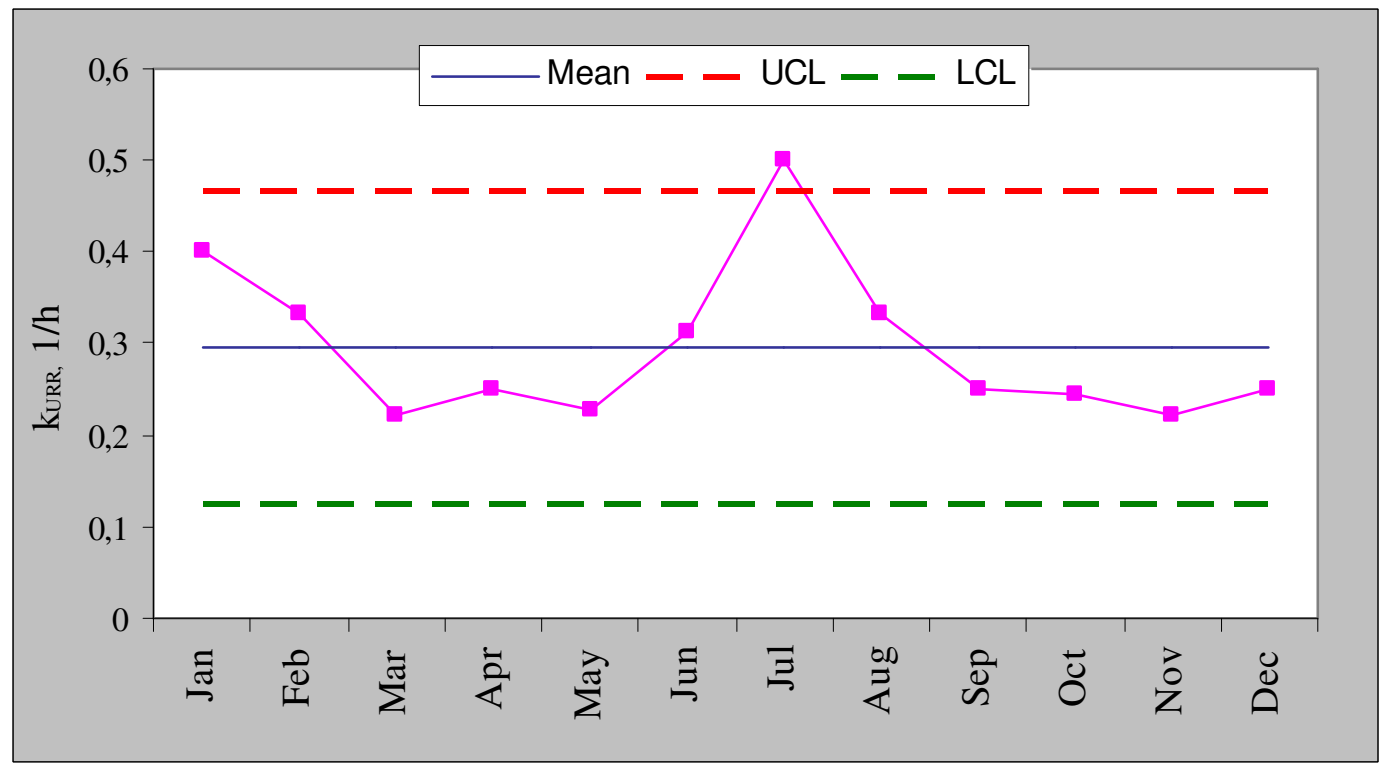

Fig 1. Control diagram of $k_{U R R}$

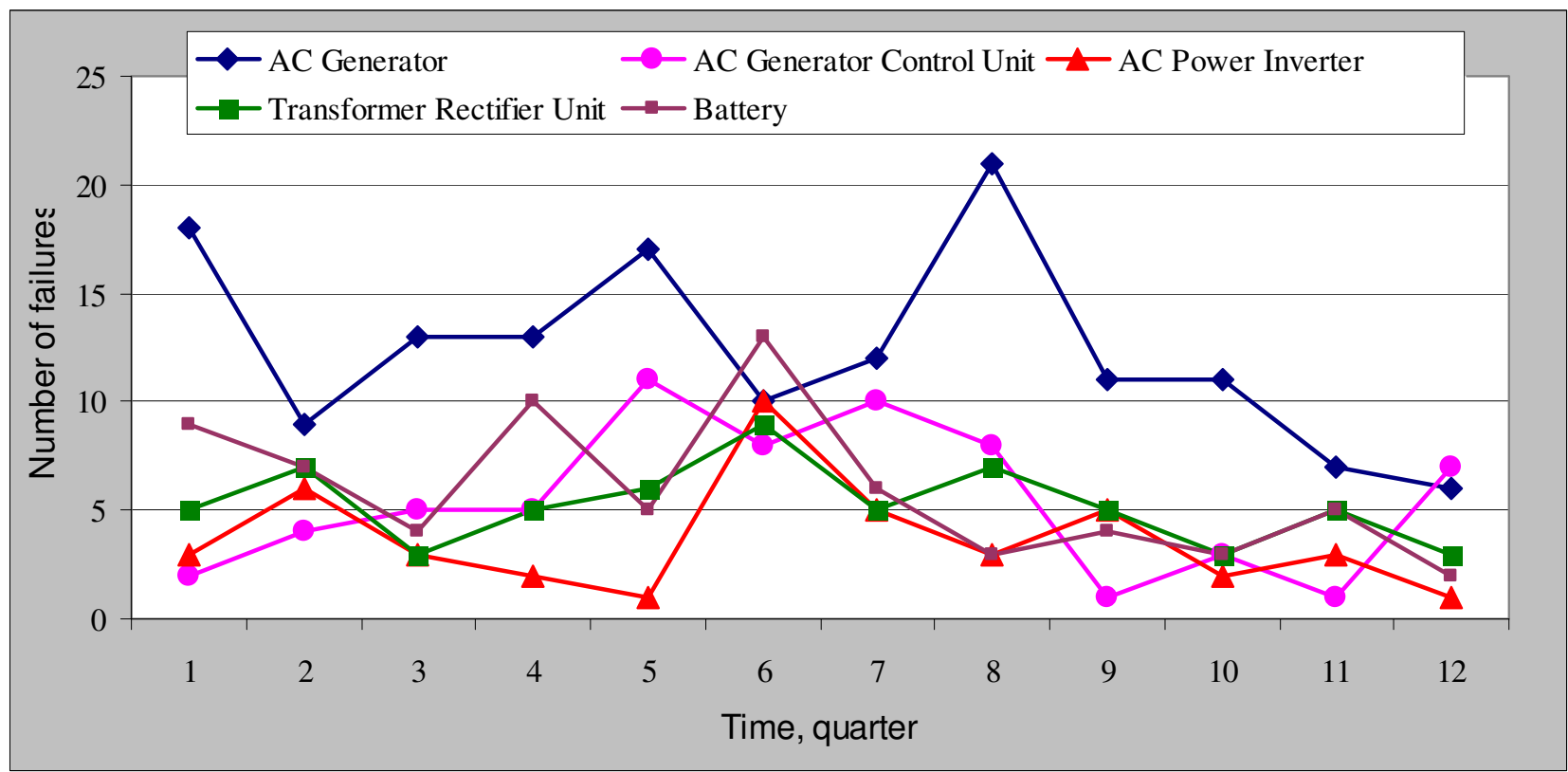

Fig 2. Diagram of failures of electrical system of an aircraft

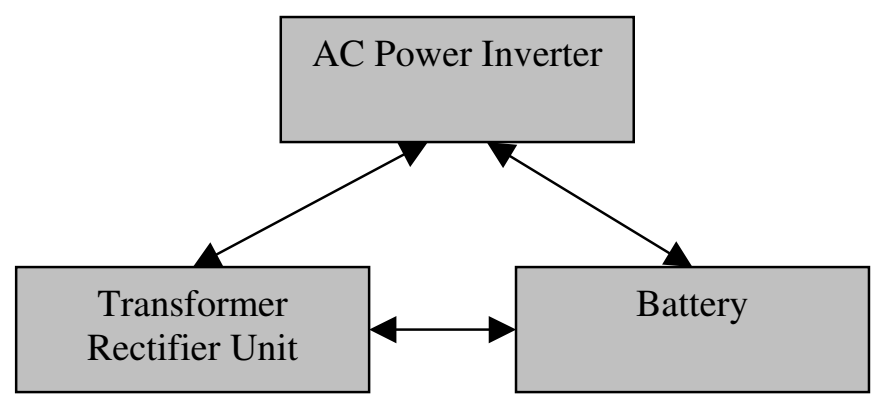

Fig 3. Mutual relationship of components of electric system 
The mutual relationship of the components is shown in figure 3, and the graphs of the regression analysis are shown in figure 4.

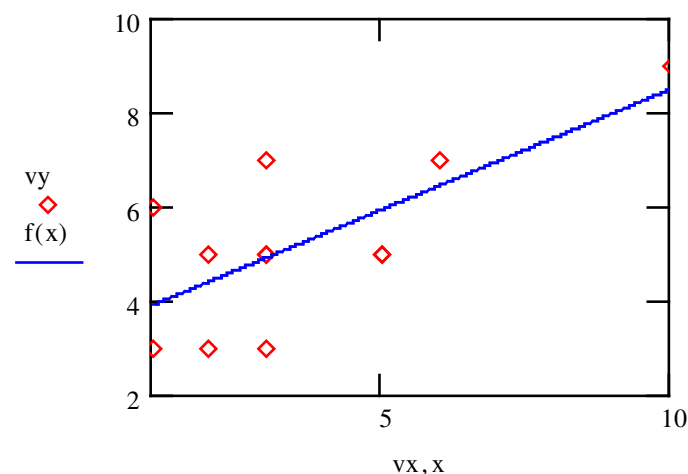

(a)

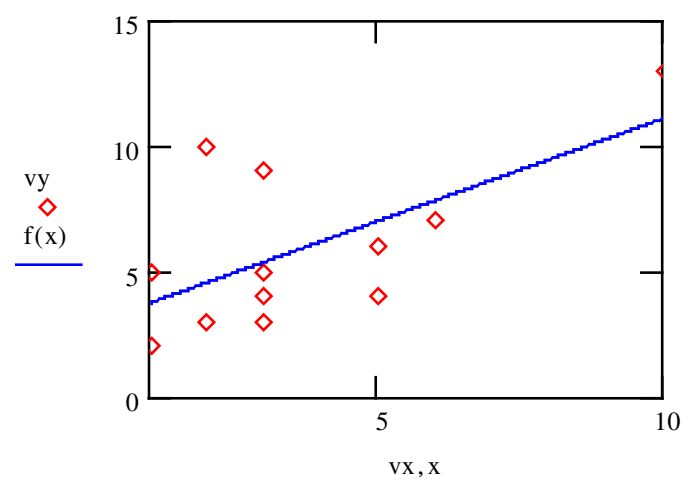

(b)

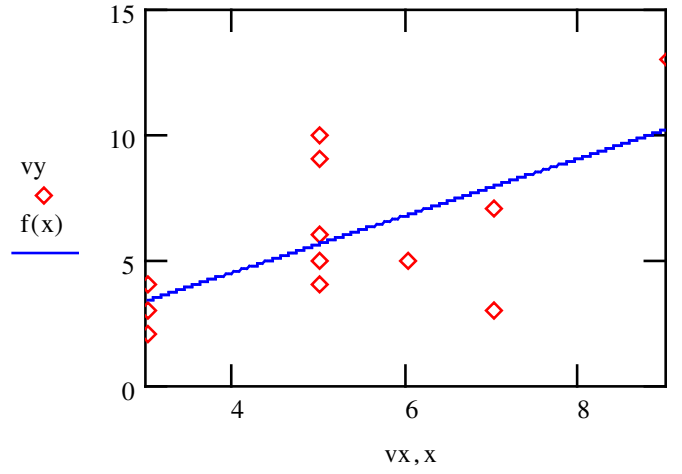

(c)

Fig 4. Mutual regression dependencies between: (a) - the AC Power Inverter (X) and the Transformer Rectifier Unit; (b) - the AC Power Inverter (X) and the Battery (Y); and (c) - the Transformer Rectifier Unit (X) and Battery

Correlation coefficients are $\mathrm{r}_{\mathrm{xz}}=0.6291, \mathrm{r}_{\mathrm{xy}}=0.7113$, and $\mathrm{r}_{\mathrm{yz}}=0.6283$. Then $a$ and $b$ will be

$$
a=0.4783 \text { and } b=0.6629 \text {. }
$$

After solving the equation (6), we will receive this expression of equation (5):

$$
z=0.4783 x+0.6629 y+0.6827
$$

Graphical presentation of this equation is presented in figure 5 .

\begin{tabular}{|c|c|c|c|c|c|c|c|c|c|c|c|c|c|c|}
\hline \multirow{2}{*}{ Component } & \multicolumn{12}{|c|}{ Duration, quarter } & \multirow{2}{*}{$\begin{array}{l}\text { Mean } \\
\text { value }\end{array}$} & \multirow{2}{*}{$S$} \\
\hline & 1 & 2 & 3 & 4 & 5 & 6 & 7 & 8 & 9 & 10 & 11 & 12 & & \\
\hline AC Power Inverter $(\mathbf{x})$ & 3 & 6 & 3 & 2 & 1 & 10 & 5 & 3 & 5 & 2 & 3 & 1 & 3.6667 & 2.5346 \\
\hline Transformer Rectifier Unit (y) & 5 & 7 & 3 & 5 & 6 & 9 & 5 & 7 & 5 & 3 & 5 & 3 & 5.25 & 1.8153 \\
\hline Battery $(\mathbf{z})$ & 9 & 7 & 4 & 10 & 5 & 13 & 6 & 3 & 4 & 3 & 5 & 2 & 5.9167 & 3.2879 \\
\hline
\end{tabular}

Table. Data of mutually dependant components

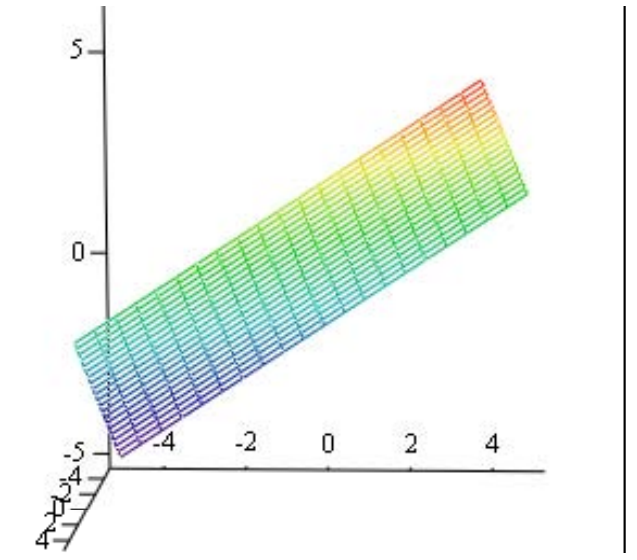

Fig 5. Regression plane of AC Power Inverter (X), Transformer Rectifier Unit (Y), and Battery (Z) 
According to formulae (7) and (8) the correlation coefficients can be determined:

$$
\mathrm{R}=0.6797, \mathrm{r}_{\mathrm{xz}(\mathrm{y})}=0.3332, \mathrm{r}_{\mathrm{yz}(\mathrm{x})}=0.3309 .
$$

As can be seen from the correlation analysis, a middle strength relationship exists between the AC Power Inverter, the Transformer Rectifier Unit, and the Battery. Partial correlation sample coefficients show a weak relationship between the Battery and AC Power Inverter (at the invariable coefficient of the Transformer Rectifier Unit) and between the Battery and the Transformer Rectifier Unit (at the invariable coefficient of the AC Power Inverter). This means that after a full analysis of the mutual relationships of the components under consideration, some correctional actions can be undertaken. Before taking any actions on the aircraft components, the user must first contact the aircraft producer, since they know the most about the product.

\section{Conclusions}

- The aircraft maintenance programme must be optimized using the elements of mathematical statistics involving the diagnostics of technical parameters and other maintenance operations to reduce the costs of aircraft maintenance.

- It is shown that there are possibilities to make an optimization of the maintenance programme and to prevent a decrease in the reduction in the limits of endurance of aircraft systems/components by performing correctional actions to approach the maximal characteristic endurance limit. There are no means to raise the entire endurance limit during the exploitation of the aircraft.

- Statistical methods, such as correlation and regression analyses help to review the separate components as an entire entity and search for mutual relations and failure possibilities.

- The application of statistical methods such as correlation and regression analyses enables the endurance limit of the aircraft and its reliability to be increased. These data can be presented to the producer and user of the aircraft for making corrections in the organization of maintenance.

\section{References}

1. Adomėnas V. Statistiniai kokybès valdymo metodai. - Kaunas: Technologija, 2000. - 254 p.

2. Amsden R.T., Buttler H.E., Amsden D.M. SPC Simplified: Practical Steps to Quality. New York: Quality Resources, 1986. - P. 262.

3. Barczyk C.C. Visuotinès kokybès vadyba (Total Quality management). - Vilnius: Eugrimas, 1999. -255 p.

4. Boeing Commercial Airplanes Group. Maintenance reliability and cost analysis seminar material. - 2002.

5. BS 3800: General tests of machine tools.

6. BS 3800: Statistical methods for determination of accuracy and repeatability of machine tools. 1991. -Part 2.

7. BS 4656: Accuracy of machine tools and methods of test.

8. Čekanavičius V., Murauskas G. Statistika ir jos taikymai. - Vilnius: Leidykla TEV, 2000. $238 \mathrm{p}$.

9. Doebelin E.O. Measurement systems // Application and design. - New York - London, 1990. - IV Ed. - P. 960.

10. EN ISO 9000: Quality Assurance and Management System.

11. Figliola R.S., Beasley D.E. Theory and design for mechanical measurements. - 1991.

12. Guide to Expressions of Uncertainty in Measurement - GUM. - ISO Publishing, 1995.

13. ISO 8402: Quality management and quality assurance. Vocabulary (ISO 8402). - 1995.

14. ISO 9002: 1995 Quality systems - Model for quality assurance in production, installation and servicing.

15. Medekšas H. Gaminių kokybė ir patikimumas. - Kaunas: Technologija, 2003. - 279 p.

16. Quality management systems: Requirements (ISO 9001). - 2000.

17. Бикел П., Доксам К. Математическая статистика. - Москва, 1983. - 251 с.

18. Гмурман В.Е. Теория вероятностей и математическая статистика. - Москва. 1977. -479 c. 
Attachment. Results from regression and correlation analyses of components of electrical system

\begin{tabular}{|c|c|c|c|c|c|c|}
\hline & & 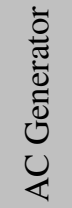 & 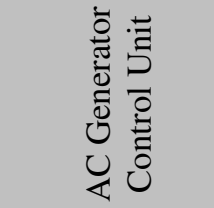 & 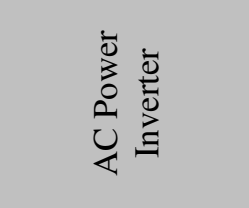 & 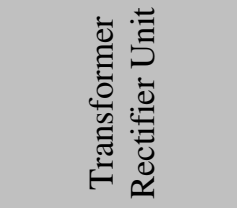 & 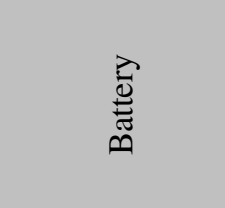 \\
\hline \multirow{4}{*}{ 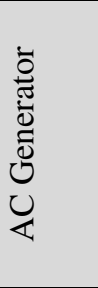 } & Regression equation & \multirow{4}{*}{ N/A } & $y=2.691+0.221 x$ & $y=5.114-0.117 x$ & $y=4.122+0.0915 x$ & $y=5.616+0.0244 x$ \\
\hline & Correlation coefficient $\mathrm{r}$ & & 0.2901 & -0.2065 & 0.2246 & 0.03307 \\
\hline & $\begin{array}{l}\mathrm{t} \text { criterion of the } \\
\text { component }\end{array}$ & & 0.9587 & -0.6673 & 0.729 & 0.1046 \\
\hline & $\begin{array}{l}\text { Mutual interaction } \\
\text { (yes/no) with probability } \\
\text { of } 95 \% \text { and degree of } \\
\text { freedom } n-2=10\end{array}$ & & NO & NO & NO & NO \\
\hline \multirow{4}{*}{ 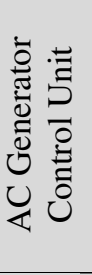 } & Regression equation & \multirow{4}{*}{ N/A } & \multirow{4}{*}{ N/A } & $y=3.553+0.0210 x$ & $y=4.364+0.163 x$ & $y=5.643+0.0506 x$ \\
\hline & Correlation coefficient $\mathrm{r}$ & & & 0.02816 & 0.3059 & 0.05223 \\
\hline & $\begin{array}{l}\text { t criterion of the } \\
\text { component }\end{array}$ & & & 0.08908 & 1.01611 & 0.1654 \\
\hline & $\begin{array}{l}\text { Mutual interaction } \\
\text { (yes/no) with probability } \\
\text { of } 95 \% \text { and degree of } \\
\text { freedom } n-2=10\end{array}$ & & & NO & NO & NO \\
\hline \multirow{4}{*}{ 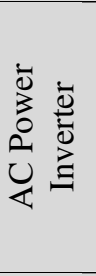 } & Regression equation & \multirow{4}{*}{ N/A } & \multirow{4}{*}{ N/A } & \multirow{4}{*}{ N/A } & $y=3.382+0.509 x$ & $y=2.925+0.816 x$ \\
\hline & Correlation coefficient $r$ & & & & 0.7113 & 0.6291 \\
\hline & $\begin{array}{l}\text { t criterion of the } \\
\text { component }\end{array}$ & & & & 3.1999 & 2.5590 \\
\hline & $\begin{array}{l}\text { Mutual interaction } \\
\text { (yes/no) with probability } \\
\text { of } 95 \% \text { and degree of } \\
\text { freedom } n-2=10\end{array}$ & & & & YES & YES \\
\hline \multirow{4}{*}{ 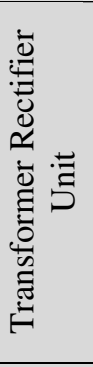 } & Regression equation & \multirow{4}{*}{ N/A } & \multirow{4}{*}{ N/A } & \multirow{4}{*}{ N/A } & \multirow{4}{*}{ N/A } & $\begin{array}{l}y=-0.0575+ \\
1.138 x\end{array}$ \\
\hline & Correlation coefficient $r$ & & & & & 0.6283 \\
\hline & $\begin{array}{l}\mathrm{t} \text { criterion of the } \\
\text { component }\end{array}$ & & & & & 2.5537 \\
\hline & $\begin{array}{l}\text { Mutual interaction } \\
\text { (yes/no) with probability } \\
\text { of } 95 \% \text { and degree of } \\
\text { freedom } n-2=10\end{array}$ & & & & & YES \\
\hline \multirow{4}{*}{ 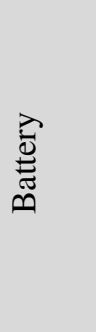 } & Regression equation & \multirow{4}{*}{ N/A } & \multirow{4}{*}{ N/A } & \multirow{4}{*}{ N/A } & \multirow{4}{*}{ N/A } & \multirow{4}{*}{ N/A } \\
\hline & Correlation coefficient $\mathrm{r}$ & & & & & \\
\hline & $\begin{array}{l}\text { t criterion of the } \\
\text { component }\end{array}$ & & & & & \\
\hline & $\begin{array}{l}\text { Mutual interaction } \\
\text { (yes/no) with probability } \\
\text { of } 95 \% \text { and degree of } \\
\text { freedom } n-2=10\end{array}$ & & & & & \\
\hline
\end{tabular}

